\title{
ESTRUTURA POPULACIONAL DE NOTODIAPTOMUS AMAZONICUS (COPEPODA: CALANOIDA) EM UM LAGO AMAZÔNICO URBANO NO LAVRADO DE RORAIMA
}

\author{
Geraldes-Primeiro, L. J. O. ${ }^{1,}$; , Santos-Silva, E.N. ${ }^{1}$; Carvalho, C.M. ${ }^{1}$; Faria, R.E.S. ${ }^{2}$; Silva, F. R. S. ${ }^{2}$; \\ Nascimento, R.G. ${ }^{1}$; Mendes, R. C. ${ }^{1}$ \& Cruz, L.R.B. ${ }^{3}$ \\ ${ }^{1}$ Instituto Nacional de Pesquisas da Amazônia (INPA), Campus II - Aleixo, Laboratório de Plâncton. \\ ${ }^{2}$ Instituto Nacional de Pesquisas da Amazônia (INPA), Campus Boa Vista, Roraima. \\ ${ }^{3}$ Universidade Federal de Roraima, Campus Boa Vista, Roraima. \\ *Autor correspondente: luis.primeiro@inpa.gov.br
}

\begin{abstract}
Neste estudo foi investigado a história natural do copépode Notodiaptomus amazonicus, a única espécie encontrada em um lago urbano de área preservada no lavrado de Roraima, norte da Amazônia. Esses são organismos que possuem grande importância ecológica para os ambientes lacustres da região e representam uma lacuna no conhecimento sobre esse ecossistema amazônico de campos abertos, distinto por seus lagos dentro do domínio morfoclimático da Hileia. Dessa forma, a proporção dos estágios ontogênicos (náuplio, copepódito e o adulto) dentro da estrutura populacional da espécie foi estudada sob a influência da variação do nível da água do sistema aquático. As amostragens foram feitas em seis coletas a cada cinco dias durante a estiagem na região (dezembro-janeiro de 2015), abrangendo três fases correspondentes ao nível da água: (1) fase cheia, (2) período intermediário (entre cheio-seco) e (3) fase seca. Em campo as coletas foram quantitativas e utilizou-se coletor Schindler/Patalas $(50 \mu \mathrm{m}-12 \mathrm{~L})$ em 12 pontos aleatórios em cada coleta. O material foi fixado com formalina 4\%. Em laboratório os organismos foram identificados e as fases de vida quantificadas através de estereoscópio ótico binocular (Zeiss, 1x-40x). A análise dos dados seguiu a práxis estatística através do teste Qui-Quadrado para proporções ( $P>0,05 \%$ ). As três hipóteses inicialmente consideradas para homogeneidade na ocorrência individual de náuplios, copepóditos e adultos entre as três fases foram refutadas. Para náuplios a densidade foi na ordem fase $1>$ fase $2>$ fase 3 , com proporção $6: 5: 2\left(\chi^{2} 0.05,1=1.1750, p>0,05\right)$. Copepódito apresentou densidade na ordem fase $2>$ fase $1>$ fase 3 , com proporção 9:7:6 ( $\chi^{2}$ 0.05, $\left.1=4.7331, p>0,05\right)$. Adultos apresentaram a densidade fase $1>$ fase $2>$ fase 3 , com proporção 10:7:6 ( $\chi^{2} 0.05,1=1.8319, p>0,05$ ). Os resultados sustentaram a influência direta da variação do nível da água do ambiente sobre as densidades das fases de vida observadas e evidenciaram uma estrutura populacional da espécie diferente de outros copépodes calanóides descritos para a Amazônia, onde o padrão apresentado foi copepoditos e adultos prevalecendo sobre os náuplios do ambiente estudado.
\end{abstract}

Palavras-chave: história natural, zooplâncton, estágios ontogenéticos, lago do Lavrado, Boa Vista-RR. 